\title{
Service Learning: What's a Political Scientist Doing in Yonkers?
}

\author{
Glenn Beamer, University of Virginia and University of California, Berkeley
}

\begin{abstract}
A $\mathrm{s}$ an urban politics teacher, I discerned a disconnect between what I said about urban politics and what my students understood. Although I offered a variety of perspectives, I nonetheless felt that students were coming to class, and leaving class, with their opinionsliberal, conservative, and in-between -formed. Because of the constraints on dialogue about urban politics, I decided to develop a service learning project focusing on urban homelessness and housing. The project would combine elements of a typical undergraduate course and a participant observation project. I wanted a setting in which the students and I would learn together about urban policy problems and better understand their complexity. The shared experience of working in an urban neighborhood for a week would, in a sense, serve as a text, although this "text" would be experienced and discussed contemporaneously.

The experiential learning project offered several pedagogical advantages. Markus, King, and Howard (1993) found that students who participated in community service in conjunction with a contemporary issues lecture course reported higher motivations to continue community service and higher levels of individual efficacy vis-á-vis their abilities to make a difference in their communities following the experiential learn-
\end{abstract}

Glenn Beamer is currently a scholar in the Robert Wood Johnson Scholars in Health Policy Research Program at the University of California, Berkeley. He is on leave from the University of Virginia, where he is an assistant professor in the department of government and foreign affairs. He can be reached via email at gbeamer@socrates.berkeley.edu. ing program. In comparison to students who took only the lecture course, the service learning students in the Markus, King, and Howard experiment reported greater understanding of connections among normative principles and possible applications, greater awareness of societal problems, greater frequency of reconsidering attitudes, and greater sense of personal responsibility. For the project at University of Virginia, my goals went beyond providing a few hours of community service to developing a model in which the students would integrate classroom learning with community experience and come away with a better sense of how to make improving their communities a part of their careers (Barber and Battistoni 1993).

I proposed a service learning project to the Greyston Foundation of Yonkers, New York, which both the foundation and UVA accepted. Greyston offered several advantages for a service learning project. The on-site Greyston Bakery provides job training and employment to 65 formerly homeless individuals from Yonkers. Employees at the Bakery earn at least $\$ 6.50$ an hour and receive health insurance. With bakery profits, Greyston supports the Greyston Family Inn, which currently provides 28 refurbished apartments to lower income families, and they are refurbishing 22 additional apartments. At the Greyston Family Inn is the Greyston Day Care which provides subsidized day care services. Greyston is converting a former convent into a permanent housing and health facility for AIDS and HIV+ individuals. In one site, I found an organization that was addressing several components of the welfare trap-homelessness, high housing costs, employment, health insurance, job training, and child and health care. In coordinating the project with Greyston, their personnel and I emphasized that Greyston was a partner in the students' education. Greyston became a full partner in the pedagogy of experiential learning and not simply a forum in which the students could perform several hours of community service (Barber and Battistoni 1993).

The program's financing became a key means for involving the students in planning the program-a goal I had adopted in an effort to increase the collaboration and collegiality of the experience (Barber and Battistoni 1993). Making students responsible for the program's finances transformed the project from one of altruistic service to a more concrete academic project in which budgets had to be met or the class would fail. The university's Undergraduate Academic Affairs office provided about $25 \%$ of the funding. My department provided transportation funds, and over $50 \%$ of the funding came from the students themselves. We arranged a benefit band night with a local restaurant, and each student committed to selling tickets. Consequently, we fully funded the program with no student being precluded from participating because of individual financial constraints. The students' efforts produced a surplus that we donated to Greyston and Habitat for Humanity. In any future programs, I would again involve the students in program planning. Doing so in the Greyston project helped them take ownership of the project in a way they would not have had I employed a "top-down" approach to the experiential learning. 


\section{The Program}

Prior to leaving for Yonkers, the students and I met as a seminar using Christopher Jencks's The Homeless (1994), and selections from Wilson's The Truly Disadvantaged (1987, chap. 3), Danziger and Gottschalk's American Unequal (1995, chaps. 1, 2), and Bane and Ellwood's Welfare Realities: From Rhetoric to Reform (1994, chaps. 4, 5). Jencks provided a basis for understanding the breadth and complexity of the homeless population. Wilson and Danziger and Gottschalk provided overviews of the "macro" urban environment and the problems of poverty, unemployment, and income inequality. Wilson also provided a theoretical model for understanding the causes of concentrated urban poverty. Bane and Ellwood familiarized the students with the "welfare trap."1

The week in Yonkers was analogous to a text that the students would "read" involuntarily and that the instructor could not read ahead of anybody else. Comparing the experiential component to an additional scholarly work is a useful point of departure to explain how experiential learning can complement the more traditional classroom experience and to identify some of the limits of experiential learning. At a minimum, the on-site service learning in Yonkers transformed the student-teacher relationship from one of unidirectional knowledge transfer to one of collaborative knowledge creation (McClintock 1993).

With the commencement of the program in Yonkers, I sought to address three pedagogical goals directly engaged by service learning (Buchen 1995): 1) understanding causality, 2) understanding what can be changed in a real-life situation, and 3 ) integrating knowledge and strategies for change.

The service learning program itself had three daily components: morning seminars, afternoon volunteer activities, and evening review sessions. These activities facilitated achievement of the three goals. The participant observation via volunteer activities encouraged understanding of the causes of poverty. The morning seminars contributed to understanding what factors governments and private for-profit and not-forprofit organizations could manipulate to address urban problems. These seminars also gave the students insights into policies and approaches that had failed at Greyston. The evening review sessions provided critical time to synthesize our daily observations and experiences and integrate them with the theoretical and empirical knowledge we acquired prior to going to Yonkers.

\section{Understanding Causality}

The causes of concentrated poverty were brought into relief, paradoxically, by a largely vacant fenced high-rise condominium project on the banks of the Hudson River. The students discussed how this condominium complex would have done nothing to change the fundamental economic needs of many people in southwest Yonkers and would have likely housed commuters who held high-paying jobs in Manhattan. The students also discerned the displacement of public areas and lower-cost private housing that would be created by such "gentrification."

The service activities-working a shift in the bakery, clearing garden plots, and painting the child care center-afforded opportunities to understand how to successfully ameliorate poverty. They gave students a sense of what "causes" one to leave poverty. In sessions with bakery supervisors, the students learned how low wages, high child care costs, or a lack of health care coverage could nearly force a worker attempting to break a cycle of poverty back onto public assistance in order to care for a child or qualify for Medicaid benefits. Experiencing relatively high grocery prices and transportation challenges in the metropolitan New York area gave the students a better understanding of the economics of urban America than they could gain in Charlottesville. Several of the students came away from the program advocating greater governmental support for child care and health care reforms that would not leave low-wage workers facing choices between working, caring for children, and qualifying for health insurance.

The service activities illuminated how the various interventions interacted to facilitate an individual's or family's escape from poverty, unemployment, or homelessness. In other words, the participant observation conferred validity on the interventions conducted by Greyston-facilitating understandings of causality, of which variables mattered, and of how policies interacted for different individuals and families.

\section{Understanding Variables and What Can Be Changed}

The morning seminars provided the forum in which we gained the best understanding of the various parameters in which Greyston operated. The program directors from the foundation's neighborhood operations, finance, administrative, and development offices all met with the students. Students learned not only where and how Greyston succeeded, but also when and why programs failed. Although they did not observe a "failure" first hand, the students raised tough questions about the likely operation of the AIDS hospice center and they learned from practitioners who had experienced Greyston's failures with various products at its bakery. For example, early efforts to run the bakery as a specialty shop had limited the bakery's ability to offer entry-level employment. The bakery gained financial stability and better achieved its employment and training goals after securing a contract to provide Ben and Jerry's Ice Cream with chocolate fudge brownies for their Fudge Brownie Ice Cream-a product line that generated more entry-level employment.

Learning about failure from practitioners was a decided benefit of the on-site program. By meeting with practitioners, students could delve into the "hows" and "whys" of failure. Using the analogy of a text, the meetings in Yonkers enabled the students to go beyond the material 
many Greyston personnel had prepared and the seminars became somewhat like working with unedited manuscripts that could be annotated based on the students' questions. Learning about programs that failed was akin to having the students meet with diplomats to discuss wars averted (Achen and Snidal 1989) or learning from citizen groups who had failed to overcome the collective action barriers to creating a local government (Burns 1994).

One variable the students identified as important was time. The onsite experience helped students appreciate the temporal components of urban politics. Even when describing events taking place over time, traditional scholarship may not explicitly model the role of time in policy interventions. ${ }^{2}$ Early in the week, the students noticed that few of the children at the Greyston Child Care Center lived in the housing at the Greyston Family Inn. The center director and volunteer coordinator explained that when the apartments at the Greyston Family Inn opened eight years ago, all of the children served by Greyston's child care did live in Greyston housing. However, because of the success of the Family Inn at creating secure, affordable housing and because $90 \%$ of the original inhabitants had remained, their children had grown up and no longer needed day care services. This created a challenge, and Greyston responded by offering subsidized child care to all families in the neighborhood while maintaining its permanent housing program.

Our work in and around the bakery led to a consensus among our group that "solving the welfare trap" takes significantly longer than political debate and even academic research has indicated. The bakery sales director suggested that someone leaving homelessness may work for three years in the bakery before he or she achieves financial and personal stability. The bakery managers encourage employees to enroll in training and education programs that will enable them to leave the bakery and enter occupations paying $\$ 10$ to $\$ 20$ per hour as opposed to the $\$ 8$ an hour that the bakery pays to most of its shift workers. The management pays up to $\$ 12$ to $\$ 14$ per hour for high-skilled pastry chefs, but there are few positions.

We also worked cleaning a site on the Hudson River that would be used as an "Urban Garden" project. As with the child care center, the garden project illuminated the role time played, albeit in a less uplifting way. Prior to taking us to the site to clear it for seeding, the project director took us to a site in its first year of a five-year "soil rehabilitation" treatment designed to reduce the toxicity and acidity of the soil so it would regain its fertility. When one of the students commented that she could not imagine working five years on a plot before being able to grow anything in it, another replied that he could not imagine how many years of pollution and neglect had caused the soil to degrade so badly in the first place.

The garden project exposed students to factors important to creating a livable environment that are quite appropriately omitted from poverty and employment models but affect the quality of life. Although urban gardens may create few jobs and may not be measurable as a variable in a model of residents' neighborhood satisfaction, the students concluded such projects were necessary to renew the community and economy of southwest Yonkers. The students perceived the gardens as a means for residents to gain a stake in their community and a forum in which to become acquainted with one another. As one student wrote in her final paper:

\begin{abstract}
Although his garden projects did not solve homelessness, they did establish community and connected various members from around the community. The result of such projects is trust and respect that can lead to mobilization and organization within the community.
\end{abstract}

At the garden site, the students realized that revitalizing and reinvigorating communities necessitates attending to the physical environment of the community and not reliance upon national programs or pri- vate charities for large-scale employment programs-a point made much more emphatically by clearing trash than by attending one of my lectures.

Our evening discussions facilitated the students' understandings of what can be changed to address social problems. Conversations with program directors and participation in the programs themselves enabled students to conceive of what variables federal, state, and local governments could manipulate to address urban unemployment, child care, affordable housing, transportation, and health care. Students understood how actions by one level of government could preclude or encourage actions by a second level of government. For example, in a vigorous conversation with a bakery worker, the students learned that wages below $\$ 8$ per hour would not support a family in the absence of subsidized child care for a single parent. This conversation led to a consensus among the students that the welfare reform may unfortunately contribute to homelessness or unemployment if parents face low wages, high child care costs, and strict time limits on cash assistance benefits.

\section{Integrating Knowledge and Action to Develop Strategies for Change}

Based on the students' course evaluations, the largest benefit of the Yonkers program came from integrating knowledge and action. By meeting people and discussing their situations and challenges, the students could discuss the advantages and disadvantages of policy options in a more tangible way than secondhand case evidence allows. The strongest evidence of this was the convergence of opinion about the roles of both government and the private sector in southwest Yonkers. Going into the program, one of the students favored "more government" and saw the private sector as a drain on the neighborhood. At the opposite end of the spectrum, another student consistently propounded "getting government out of the way," 
and "letting the market work." By week's end, both students supported mixed public-private policies for urban problems. As an example of such policies, the bakery sales director explained that the child care subsidies were bakery profits that the employees voted to commit to the child care center. All seven students and myself agreed for-profit firms had a role to play in urban areas. With respect to government, the students agreed that government regulation of wages and tax credits for the working poor were critical components for "leveling the playing field" such that firms like the Greyston Bakery could be profitable while competing for business in the New York metropolitan area.

In a direct connection with our seminar preparation, the bakery president gave his own "hands-on" review of Wilson's The Truly Disadvantaged and argued that Wilson had correctly diagnosed the causes of urban poverty but had misdirected the solution toward federal notfor-profit jobs programs. He argued that only by having a profitable bakery could the founda-

When service learning is integrated with more traditional pedagogies, it presents a potent means to expose students to the "qualitative" and "quantitative" approaches of political science in a healthy manner that demonstrates their complementarity. tion shift profits to child care subsidies for the Greyston Family Inn. The bakery CEO challenged Wilson's prescription for urban poverty without challenging his underlying theory about the causes of concentrated urban poverty. In later discussing the president's challenge to Wilson, the students agreed that their assessment of his experiences would lead them to also question Wilson's call for a federal full-employment policy.

In the seminars, the students often asked "empirical" questions about toni 1993). how things worked, how many people were served, and at what cost. Our evening sessions afforded an opportunity to connect these empirical questions and answers with theories and "macro" evidence we studprior to the trip. Using the halfcant high-rise condominium as a mol, several students discussed how attracting wealthy people to the no worked, shopped, and recreated elsewhere would do would accelerate income inequality in the area. We discussed the need to offer affordable, desirable housing such that the formerly homeless would remain in the neighborhood after their increased wages enabled them to leave southwest Yonkers. In the absence of such housing programs, Greyston's employment and training programs could contribute indirectly to an exodus of the Yonkers' working class thus creating concentrated poverty (Wilson 1987).

\section{Discussion}

After returning from Yonkers, we conducted three additional seminar sessions, and the students wrote papers in which they integrated theory, empirical data, and their experiences. This synthesis indicates that, while service learning works well as a component in undergraduate pedagogy, it should not stand alone from, nor replace, more traditional learning activities involving primary research and discussion of social science theories (Corder 1991; Barber and Battis-

The Yonkers experience provided students with a richer context in which to understand theories such as Wilson's (1987), and it gave concrete examples of phenomena described by Danziger and Gottschalk (1995) and Bane and Ellwood (1994). However, had we gone to Yonkers without studying these scholars' theories and findings, the students would not have had a basis for evaluating the programs and problems they observed. Thus, the two components, traditional scholastic learning and experiential learning, became interdependent.

Logistics dictated that I could only take seven students to Yonkers, and this limitation merits discussion. Had Greyston offered to accommodate more students, I am uncertain I would have increased enrollment. A larger number of students would have changed the nature of our observation and likely decreased the extent of informal interactions among the students and different individuals at Greyston. Nonetheless, a legitimate concern is the concentration of resources on seven students. The total cost of the program was about $\$ 1000$ (or $\$ 140$ per student) and, again, the students raised the funds such that no student had to pay out-of-pocket beyond the tuition charged for any course.

In an effort to broaden the benefits of the course to students who could not experience Yonkers, several students and I worked to produce a video documentary about Greyston and Yonkers. Producing this video created several benefits. It literally focussed the students on the speakers and activities. The video provided a means to review the trip, and it further encouraged the students to consider the whole week in Yonkers an academic research enterprise more than a week of volunteer service to an "underprivileged" neighborhood. We worked together to produce a twenty-minute edited documentary from the original tape. Along with a CBS News segment about Greyston, I can use the edited video in urban politics classes. In a trial presentation, students who had not gone to Yonkers identified their peers as the "researchers" from the video and appeared more enthused about discussing the problem than when I referred to a printed syllabus. ${ }^{3}$ 
As a researcher, I found the largest benefit of the program to be that the students identified interestingquestions that I would not have. The students' interest in time as a component of policy and politics made me rethink how I would develop future models regarding community development and urban policy. As a teacher, I found the benefit to be one of integrating theory and policy with the students and not simply having them evaluate my proposals or others' scholarship. The students recognized that research and teaching are different modes with the same objectives of gaining and disseminating knowledge (King, Keohane, and Verba 1994). For my own scholarship, I learned the importance of meeting with practitioners not only to inquire about their experiences but to gain the benefit of their evaluations. I had not expected the bakery president

\section{Notes}

1. An added benefit of working with the Greyston Foundation was that its founder, Roshi Bernard Glassman, coauthored a book, Instructions to the Cook (1996), depicting Greyston's history and its efforts to revitalize southwest Yonkers. The students and I read this book as part of our preparation for going to Yonkers.

2. I am not suggesting that the models should to have a detailed critique of William Julius Wilson at the ready when we met. His critique was valuable for me to hear because it emphasized the need for me to interact with practitioners in both conducting and presenting research.

Perhaps the largest benefit of the program came from the increased thoughtfulness and dialogue among the students. The students' emphasis on time and process returned in many of their final papers as several wrote about integrating their professional careers in law, finance, education, and social work with their goal of working to improve communities like southwest Yonkers. By helping the students recognize the ongoing nature of community development, the program may have laid the groundwork for the students to integrate community develop- ment work into their professional lives instead of occasionally volunteering and viewing such work as charity or altruism in which they "give something back" to a community they consider underprivileged (Markus, King, and Howard 1993; Barber and Battistoni 1993).

When service learning is integrated with more traditional pedagogies, it presents a potent means to expose students to the "qualitative" and "quantitative" approaches of political science in a healthy manner that demonstrates their complementarity (King, Keohane, and Verba 1994). Moreover, it may be a potent means for engaging citizenship (Markus, Howard, and King 1993) and fostering students' understandings of their responsibility to their community (Barber and Battistoni 1993). encode time. Inclusion of such a variable might be extraneous or even confound a model. Rather, the on-site experience led students to suggest that models and theories of urban politics would be more realistic if they accounted for the time it takes to implement and assess policies.

3. A second means to address the space limi- tations is to establish service learning as a research strategy for a larger lecture course on campus. The drawback to this approach is that having students volunteer in their community may atomize the experience, limiting the opportunities for synthesis and integration of actions and theory. For a discussion of these trade-offs see Barber and Battistoni (1993).

\section{References}

Achen, Christopher, and Duncan Snidal. 1989. "Rational Deterrence Theory and Comparative Case Studies." World Politics 41(2): 143 69.

Bane, Mary Jo, and David T. Ellwood. 1994. Welfare Realities: From Rhetoric to Reform. Cambridge, MA: Harvard University Press.

Barber, Benjamin R., and Richard Battistoni. 1993. "A Season of Learning: Introducing Service Learning into the Liberal Arts Education." PS: Political Science and Politics 26(2): 235-40, 262.

Buchen, Irving H. Jan. 1995. "Service Learning and Curriculum Transfusion." NASSP Bulle$\operatorname{tin} 79(567)$ : $66-70$.

Burns, Nancy E. 1994. The Formation of American Local Governments: Private Values in
Public Institutions. New York: Oxford University Press.

Corder, Jim W. 1991. "Traditional Lectures Still Have a Place in the Classroom." Chronicle of Higher Education, June 12, B2.

Danziger, Sheldon, and Peter Gottschalk. 1995. America Unequal. New York: Russell Sage Foundation.

Glassman, Bernard, and Rick Fields. 1996. Instructions to the Cook: A Zen Master's Lessons in Living a Life That Matters. New York Bell Tower.

Jencks, Christopher. 1994. The Homeless. Cambridge, MA: Harvard University Press.

King, Gary, Robert O. Keohane, and Sidney Verba. 1994. Designing Social Inquiry: Scien- tific Inference in Qualitative Research. Princeton: Princeton University Press.

Markus, Gregory B., Jeffrey P.F. Howard, David C. King. 1993. "Integrating Community Service and Classroom Instruction Enhances Learning: Results from an Experiment." $E d$ ucational Evaluation and Policy Analysis 15(4): 410-19.

McClintock, Charles. 1993. "A Partnership of Discovery: Undergraduates Creating New Knowledge with Faculty." Human Ecology Forum 21(2): 6-7.

Wilson, William Julius. 1987. The Truly Disadvantaged: The Inner City, the Underclass, and Public Policy. Chicago: University of Chicago Press. 